\title{
Fast kinetics of calcium dissociation from calsequestrin
}

\author{
MARIANELA BELTRÁN*, GENARO BARRIENTOS and CECILIA HIDALGO
}

Instituto de Ciencias Biomédicas and Centro FONDAP de Estudios Moleculares de la Célula, Facultad de Medicina, Universidad de Chile, Santiago, Chile.

* Present address: Laboratorio Andrómaco S.A., Santiago, Chile

\begin{abstract}
We measured the kinetics of calcium dissociation from calsequestrin in solution or forming part of isolated junctional sarcoplasmic reticulum membranes by mixing calsequestrin equilibrated with calcium with calcium-free solutions in a stopped-flow system. In parallel, we measured the kinetics of the intrinsic fluorescence changes that take place following calcium dissociation from calsequestrin. We found that at $25^{\circ} \mathrm{C}$ calcium dissociation was 10 -fold faster for calsequestrin attached to junctional membranes $\left(k=109 \mathrm{~s}^{-1}\right)$ than in solution. These results imply that calcium dissociation from calsequestrin in vivo is not rate limiting during excitation-contraction coupling. In addition, we found that the intrinsic fluorescence decrease for calsequestrin in solution or forming part of junctional membranes was significantly slower than the rates of calcium dissociation. The kinetics of intrinsic fluorescence changes had two components for calsequestrin associated to junctional membranes and only one for calsequestrin in solution; the faster component was 8fold faster $\left(\mathrm{k}=54.1 \mathrm{~s}^{-1}\right)$ than the slower component $\left(\mathrm{k}=6.9 \mathrm{~s}^{-1}\right)$, which had the same $\mathrm{k}$ value as for calsequestrin in solution. These combined results suggest that the presence of calsequestrin at high concentrations in a restricted space, such as when bound to the junctional membrane, accelerates calcium dissociation and the resulting structural changes, presumably as a result of cooperative molecular interactions.
\end{abstract}

Key terms: calcium-binding proteins, ryanodine receptors, sarcoplasmic reticulum, calcium release kinetics, excitation-contraction coupling, skeletal and cardiac muscle.

\section{PROLOGUE}

\section{On how I met Guayo and developed a life-long interest in calcium}

I $(\mathrm{CH})$ can still remember vividly the period when, under Guayo's guidance, I first worked in calcium during the summer of 1965. I had just obtained my professional degree as a Biochemist, and Mitzy Canessa, my biochemistry thesis advisor, had invited me to work in Montemar with Guayo, who had come for the summer from the US to resume his work on squid axons. He was totally immersed in setting up from scratch an electrophysiological lab with the equipment he had brought from NIH, a daunting task considering the rather short time he had.

As a research project, he asked me to study calcium efflux from the squid giant axon. We found that decreasing temperature markedly reduced calcium efflux (Rojas and Hidalgo, 1968). This behavior suggested that an active plasma membrane calcium pump had a significant role on calcium efflux. I had gathered experience on the effects of mitochondrial inhibitors on active sodium transport in the amphibian urinary bladder, so it was almost natural for me to investigate how mitochondrial inhibitors affected calcium efflux from the axon. Surprisingly at the time, we also found that inhibition of mitochondria increased calcium efflux (Rojas and Hidalgo, 1988). We proposed that this increase was due to inhibition of active calcium accumulation into an intra-axonal compartment, which in retrospect might have been the mitochondria.

Unfortunately, the summer and the squid supply ended before I had time to

Corresponding author: Prof. Cecilia Hidalgo, Instituto de Ciencias Biomédicas, Facultad de Medicina, Universidad de Chile, Casilla 70005, Santiago 7, Chile, Tel.: (56-2) 978 6510, Fax: (56-2) 777 6916, Email: chidalgo@med.uchile.cl 
investigate whether external sodium removal affected calcium efflux, additional experiments envisioned by Guayo. So we missed the opportunity to discover the sodium-calcium exchanger of squid giant axons, which was reported in 1969 by the late Peter Baker and coworkers.

It was not easy for me to work with Guayo. Although later we became very good friends, he was under a lot of pressure at that time, a pressure that I felt acutely. Furthermore, I had decided to work on squid axons mostly by the brilliant lectures Mario Luxoro gave on this subject in the biophysics course that he taught to biochemistry students, but Guayo had no time then for theoretical discussions. He wanted results fast, so his interactions with me focused on the practical aspects of how to perform the experiments, and I was not very happy with this approach.

I returned to Montemar on the summers of the years 1967 to 1969 for my Ph.D. thesis work, but during this period I did not work again with Guayo or with calcium. Yet, he was a key person in helping me obtain a postdoctoral position at NIH in 1969, right after I had obtained my doctoral degree. I will always thank him for his extremely generous help during my doctoral thesis and later at NIH, both in personal as well as scientific aspects. Through him, I developed a keen interest in calcium, an interest I keep very much alive to this day.

For this reason, I decided to write an article in this issue in homage to Guayo on the rate of calcium dissociation from calsequestrin, a key luminal protein of the sarcoplasmic reticulum that not only allows this organelle to store significant amounts of calcium but that also seems to regulate the function of its calcium release channels.

\section{INTRODUCTION}

Calsequestrin (CSQ) - the most abundant luminal protein of skeletal and cardiac muscle sarcoplasmic reticulum (SR) - binds calcium with high capacity (40-50 moles per mol) but relatively low affinity (MacLennan and Wong, 1971; Ikemoto et al., 1972; Cozens and Reithmeier, 1984; see Beard et al., 2004, for a recent comprehensive review). These properties allow CSQ to act as an effective intra-SR $\mathrm{Ca}^{2+}$ buffer, so that when $\mathrm{Ca}^{2+}$ is transported actively back into the $\mathrm{SR}$, as required for muscle relaxation, CSQ binds $\mathrm{Ca}^{2+}$ and lowers the free $\left[\mathrm{Ca}^{2+}\right]$ inside the SR lumen to levels $\leq 1 \mathrm{mM}$. As a consequence, the SR can store large amounts of $\mathrm{Ca}^{2+}$, which can reach total concentrations of up to $20 \mathrm{mM}$ (Beard et al., 2004).

Calsequestrin is a highly acidic protein with approximately $50 \mathrm{Ca}^{2+}$-binding sites per molecule. At neutral pH, monomeric CSQ in solution undergoes significant structural changes upon $\mathrm{Ca}^{2+}$ binding (Ikemoto et al., 1972). Thus, increasing $\left[\mathrm{Ca}^{2+}\right]$ in the sub$\mathrm{mM}$ range produces a conspicuous increase in CSQ intrinsic fluorescence and induces a shift in CSQ structure from a random coil to a structure containing significant a-helical content (Ikemoto et al., 1972). Likewise, in $\mathrm{Ca}^{2+}$-free conditions, decreasing solution $\mathrm{pH}$ from 8.0 to 6.0 induces significant structural changes, as reflected in marked increases of CSQ intrinsic fluorescence; moreover, CSQ intrinsic fluorescence does not increase further following $\mathrm{Ca}^{2+}$ addition at $\mathrm{pH} 6.0$ (Hidalgo et al., 1996). These results suggest that $\mathrm{Ca}^{2+}$ and protons can both bind independently to CSQ and induce the same changes in CSQ structure that underlie the intrinsic fluorescence increase. Further increasing $\left[\mathrm{Ca}^{2+}\right]$ to levels $\geq 1 \mathrm{mM}$ causes CSQ aggregation and polymerization ( $\mathrm{He}$ et al., 1993).

In SR vesicles, CSQ forms a wide range of high molecular mass clusters (Maguire et al., 1997) and is attached to two junctional face membrane proteins, triadin, and junctin; CSQ forms a quaternary complex with the RyR calcium release channels presumably through its association with these two proteins (Guo and Campbell, 1995; Zhang et al., 1997), albeit direct interactions between CSQ and RyR also may take place (Murray and Ohlendieck, 1998). It has been proposed that the stabilization of the quaternary SR protein complex composed by CSQ, junctin, triadin and RyR requires $\mathrm{Ca}^{2+}$ (Wang et al., 1998); yet increasing $\mathrm{Ca}^{2+}$ beyond $10 \mathrm{mM}$ inhibits CSQ binding to junctin and triadin, in vitro (Zhang et al., 1997; Wang et al., 1998). 
Several reports indicate that, in addition to its role as luminal $\mathrm{SR} \mathrm{Ca}^{2+}$ buffer, CSQ also regulates the activity of $\mathrm{RyR} \mathrm{Ca}^{2+}$ release channels of skeletal and cardiac muscle (see Beard et al., 2004). Increasing luminal $\mathrm{Ca}^{2+}$ in a range that promotes $\mathrm{Ca}^{2+}$ binding to CSQ stimulates caffeine-induced $\mathrm{Ca}^{2+}$ release kinetics from skeletal SR vesicles (Ikemoto et al., 1989). Likewise, increasing luminal $\left[\mathrm{Ca}^{2+}\right]$ to $1 \mathrm{mM}$ or increasing luminal $\left[\mathrm{H}^{+}\right]$to $\mathrm{pH} 5.5$ stimulates the kinetics of $\mathrm{Ca}^{2+}$ release from skeletal SR vesicles induced by $\mathrm{Ca}^{2+}$ and ATP (Donoso et al., 1995; Donoso et al., 1996). Thus, conditions leading to an increase in CSQ intrinsic fluorescence and $\alpha$-helical content, such as increasing luminal-free $\left[\mathrm{Ca}^{2+}\right]$ to 1 $\mathrm{mM}$, stimulate the activity of RyR forming part of skeletal muscle SR vesicles, whereas conditions that cause calsequestrin to unravel and adopt the random coil configuration would cause RyR channel inhibitions from the luminal side (Hidalgo et al., 1996). Yet, when using $1 \mathrm{mM}$ free $\left[\mathrm{Ca}^{2+}\right]$ in the trans (luminal) compartment, the single-channel activity of native RyR measured in conditions that presumably allow RyR incorporation into lipid bilayers with CSQ, triadin, and junctin - is maximally inhibited by CSQ. In contrast, under the same conditions, the purified skeletal RyR is not inhibited (Beard et al., 2002). These results have been interpreted as evidence of RyR inhibition by CSQ, which would be attached to the RyR channels in bilayers in the presence of $1 \mathrm{mM}$ luminalfree $\left[\mathrm{Ca}^{2+}\right]$ (Beard et al., 2002). Since in 1 $\mathrm{mM} \mathrm{Ca}{ }^{2+} \mathrm{CSQ}$ is expected to have a significant $\alpha$-helical content, CSQ seems to affect differently native RyR when forming part of isolated SR vesicles than when incorporated in bilayers. A possible explanation for this different behavior might be that the high molecular mass CSQ clusters found in the SR lumen (Maguire et al., 1997), which might be responsible for RyR activation in $1 \mathrm{mM}\left[\mathrm{Ca}^{2+}\right]$, do not persist in bilayer experiments.

Results obtained in skinned skeletal muscle cells, which show that $\mathrm{Ca}^{2+}$ release rates depend on $\mathrm{Ca}^{2+}$ loading (Lamb et al., 2001), also support a role of CSQ in regulating RyR activity. In intact cardiomyocytes, increased or decreased cardiac CSQ expression is an important determinant of the $\mathrm{Ca}^{2+}$ storage capacity of the SR (Gyorke et al., 2004). It is noteworthy that the amplitude of depolarization-induced $\mathrm{Ca}^{2+}$ transients is significantly increased in cardiac myocytes over-expressing CSQ and radically reduced in myocytes with decreased CSQ expression. Furthermore, the duration of active $\mathrm{Ca}^{2+}$ release underlying these signals was prolonged in cells over-expressing CSQ and shortened in myocytes with decreased CSQ expression (Gyorke et al., 2004). These results strongly suggest that CSQ is an essential determinant of the $\mathrm{Ca}^{2+}$ releasing function of cardiac SR, since by influencing the duration of the release process, CSQ seems to control the amount of $\mathrm{Ca}^{2+}$ released to the cytoplasm.

The above results in intact cells indicate that CSQ appears to function as a $\mathrm{Ca}^{2+}$ reservoir readily accessible for $\mathrm{Ca}^{2+}$-induced $\mathrm{Ca}^{2+}$ release in cardiac muscle, and presumably for depolarization-induced $\mathrm{Ca}^{2+}$ release in skeletal muscle as well. $\mathrm{Ca}^{2+}$ release from the $\mathrm{SR}$ during excitationcontraction (E-C) coupling is a very fast process, especially in skeletal muscle, which is completed in the ms time range. Most luminal $\mathrm{SR} \mathrm{Ca}^{2+}$ is bound, and thus prior to release it must first dissociate from CSQ. Hence, it becomes relevant to determine the kinetics of $\mathrm{Ca}^{2+}$ dissociation from CSQ, and also to determine how fast CSQ undergoes conformational changes following $\mathrm{Ca}^{2+}$ dissociation, since these changes may affect RyR activity. In fact, in response to RyR activation by caffeine or polylysine, CSQ releases $\mathrm{Ca}^{2+}$ to the SR lumen before $\mathrm{Ca}^{2+}$ is released from the SR (Ikemoto et al., 1991). These results suggest that RyR activation is sensed by CSQ and raise the intriguing possibility that CSQ may transmit to RyR conformational changes associated with $\mathrm{Ca}^{2+}$ dissociation, modifying their activity. Yet, there are no direct measurements on the rate of $\mathrm{Ca}^{2+}$ dissociation from CSQ, so it is not known whether this process is faster than E$\mathrm{C}$ coupling or whether it becomes rate limiting. Accordingly, the aim of the present work was to measure the kinetics of $\mathrm{Ca}^{2+}$ dissociation from CSQ still attached to the junctional SR membrane or in solution. 


\section{METHODS AND MATERIALS}

\section{Isolation procedures}

Triad-enriched SR vesicles were isolated from rabbit white skeletal muscle as reported previously (Hidalgo et al., 1993). Using these vesicles as starting material, CSQ was purified as described (Cala and Jones, 1983). Junctional face membranes (JFM) were isolated as reported elsewhere (Costello et al., 1986), with some minor modifications. Briefly, Triton X-100 was added at a final concentration of $0.5 \%$ to vesicles preincubated at $4^{\circ} \mathrm{C}$ for $10 \mathrm{~min}$ in a solution containing $0.3 \mathrm{M}$ sucrose, $1 \mathrm{mM} \mathrm{CaCl} 2,20$ $\mathrm{mM}$ MOPS-Tris, $\mathrm{pH}$ 6.8. This mixture was incubated on ice for $20 \mathrm{~min}$, with vigorous stirring for $15 \mathrm{~s}$ in a Vortex mixer every 5 min and was sedimented at $48,000 \mathrm{x}$ g for 1 $\mathrm{h}$. The resulting pellet was resuspended in $0.3 \mathrm{M}$ sucrose, $1 \mathrm{mM} \mathrm{CaCl}_{2}, 20 \mathrm{mM}$ MOPSTris, $\mathrm{pH} 6.8$, frozen at $-80^{\circ} \mathrm{C}$ and used within a week after freezing. To prepare JFM without CSQ, solid Tris base and EGTA (from a stock solution of $100 \mathrm{mM}$ ) were added to thawed JFM fractions to reach $\mathrm{pH}$ 8.0 and a final concentration of $1 \mathrm{mM}$ EGTA. The mixture was incubated at $4^{\circ} \mathrm{C}$ for $10 \mathrm{~min}$, sedimented at $48,000 \mathrm{x} \mathrm{g}$ for $1 \mathrm{~h}$, and the resulting pellet was resuspended in $0.3 \mathrm{M}$ sucrose, $1 \mathrm{mM} \mathrm{CaCl}_{2}, 20 \mathrm{mM}$ MOPSTris, pH 6.8, frozen and used as above.

Determination of the kinetics of calcium dissociation from CSQ or JFM

All kinetic experiments were done at $25^{\circ} \mathrm{C}$ in a SX.18MV fluorescence stopped-flow spectrometer from Applied Photophysics Ltd. (Leatherhead, UK). Calcium concentration changes were monitored as changes in Calcium Green-2 fluorescence, with $\lambda$ ex $=506 \mathrm{~nm}$ and using a $530 \mathrm{~nm}$ cutoff filter (Oriel, Stratford, CT). To measure calcium dissociation kinetics from CSQ in solution, purified CSQ was equilibrated at $0.11 \mathrm{mg} / \mathrm{ml}$ in a solution containing $1.0 \mathrm{mM} \mathrm{CaCl}_{2}, 0.1 \mathrm{M} \mathrm{KCl}, 20$ $\mathrm{mM}$ Tris/MOPS, $\mathrm{pH}$ 7.2. At time zero, 10 volumes of this solution were mixed in the stopped flow spectrometer with one volume of a solution containing $13.2 \mathrm{mM}$ BAPTA, 1
$\mathrm{mM}$ Calcium Green-2, $0.1 \mathrm{M} \mathrm{KCl}, 20 \mathrm{mM}$ MOPS/Tris, $\mathrm{pH}$ 7.2. The resulting free $\left[\mathrm{Ca}^{2+}\right]$ was calculated as $0.64 \mu \mathrm{M}$ using the WinMaxC program (www.stanford.edu/cpatton/winmaxc2.html). To measure calcium dissociation from JFM, membranes $(3.3 \mathrm{mg} / \mathrm{ml})$ were dialyzed for $36 \mathrm{~h}$ at $4^{\circ} \mathrm{C}$ in a solution containing $2.2 \mathrm{mM} \mathrm{CaCl}_{2}, 0.1 \mathrm{M}$ $\mathrm{KCl}, 20 \mathrm{mM}$ MOPS-Tris, $\mathrm{pH}$ 7.2. At time zero, 1 volume of this solution (previously warmed to room temperature) was mixed in the stopped flow spectrometer with 10 volumes of a solution containing $0.286 \mathrm{mM}$ BAPTA, $1 \mu \mathrm{M}$ Calcium Green-2, $0.1 \mathrm{M}$ MOPS-Tris, $p H$ 7.2. The resulting free $\left[\mathrm{Ca}^{2+}\right]$ was calculated as above as $0.67 \mu \mathrm{M}$.

\section{Determination of the kinetics of CSQ or JFM intrinsic fluorescence changes}

Intrinsic fluorescence changes were monitored with $\lambda_{\mathrm{ex}}=295 \mathrm{~nm}$ and a $320 \mathrm{~nm}$ cutoff filter (Oriel, Stratford, CT). To measure the kinetics of intrinsic fluorescence changes that take place following the mixing of calcium-equilibrated CSQ with a calciumfree solution, purified CSQ was equilibrated at a final concentration of $0.11 \mathrm{mg} / \mathrm{ml}$ in a solution containing $1.0 \mathrm{mM} \mathrm{CaCl} 2,0.1 \mathrm{M}$ $\mathrm{KCl}, 20 \mathrm{mM}$ Tris/MOPS, $\mathrm{pH} \mathrm{7.2.} \mathrm{At} \mathrm{time}$ zero, 10 volumes of this solution were mixed in the stopped-flow spectrophotometer with one volume of a solution containing 13.2 $\mathrm{mM}$ BAPTA, $0.1 \mathrm{M} \mathrm{KCl}, 20 \mathrm{mM}$ MOPS/ Tris, $\mathrm{pH}$ 7.2; after mixing, the calculated initial free $\left[\mathrm{Ca}^{2+}\right]$ was $0.64 \mu \mathrm{M}$. To measure the kinetics of intrinsic fluorescence changes that take place after mixing calciumequilibrated JFM with a calcium-free solution, membranes $(3.3 \mathrm{mg} / \mathrm{ml})$ were dialyzed as above in a solution containing $2.2 \mathrm{mM} \mathrm{CaCl}_{2}, 0.1 \mathrm{M} \mathrm{KCl}, 20 \mathrm{mM}$ Tris/ MOPS, pH7.2. At time zero, 1 volume of this solution was mixed in the stopped flow spectrometer with ten volumes of a solution containing $0.286 \mathrm{mM}$ BAPTA, $0.1 \mathrm{M} \mathrm{KCl}$, $20 \mathrm{mM}$ MOPS/Tris, $\mathrm{pH} 7.2$, which gives a calculated free $\left[\mathrm{Ca}^{2+}\right]$ of $0.67 \mu \mathrm{M}$.

\section{Other procedures}

SDS-PAGE was carried out according to Laemmli (1970). Gels were stained with 
Coomassie blue or Stains-All (Campbell et al., 1983). Protein concentration was determined (Hartree, 1972) using commercial bovine serum albumin as standard.

\section{Materials}

All reagents used were of analytical grade. Bovine serum albumin, Coomassie Blue, Stains-All, and protease inhibitors (Leupeptin, Pepstatin A, benzamidine, and Phenylmethylsulfonyl fluoride) were from Sigma Chemical Co. (St. Louis, MO, USA). Calcium Green-2 was obtained from Molecular Probes (Eugene, OR, USA) and Triton X-100 from CalbiochemNovabiochem Corp. (La Jolla, CA, USA).

\section{RESULTS AND DISCUSSION}

Calcium dissociation from purified CSQ in solution

We used Calcium Green-2 to measure changes in solution $\mathrm{Ca}^{2+}$ following $\mathrm{Ca}^{2+}$ dissociation from purified CSQ. As illustrated in Figure 1, in the presence of SR vesicles, Calcium Green-2 displayed a $\mathrm{Kd}$ for $\mathrm{Ca}^{2+}$ binding of $0.98 \mu \mathrm{M}$.

A solution containing purified CSQ equilibrated in $1 \mathrm{mM}\left[\mathrm{Ca}^{2+}\right]$ was mixed 10 : 1 at time zero with a solution containing Calcium Green-2 and $13.2 \mathrm{mM}$ BAPTA. After mixing, initial $\left[\mathrm{Ca}^{2+}\right]$ (calculated as $0.64 \mu \mathrm{M}$ ) increased rapidly following a mono-exponential function with $\mathrm{k}=11.6 \mathrm{~s}^{-1}$ (Fig. 2A, trace a). Dilution of the above two solutions without CSQ did not produce a significant fluorescence change (Fig. 2A, trace $b)$. Considering that the CSQ concentration after mixing was $2 \mu \mathrm{M}$ and assuming that at $1 \mathrm{mM}\left[\mathrm{Ca}^{2+}\right]$ plus $0.1 \mathrm{M}$ $\mathrm{KCl}$ CSQ is $50 \%$ saturated with calcium $(25$ mol $\mathrm{Ca}^{2+} /$ mol CSQ), it can be estimated that solution $\left[\mathrm{Ca}^{2+}\right]$ should have increased to about $50 \mu \mathrm{M}$. But the presence of BAPTA (final concentration $1.2 \mu \mathrm{M}$ ) is expected to decrease $\left[\mathrm{Ca}^{2+}\right]$ to $0.81 \mu \mathrm{M}$, enough to induce complete dissociation of calcium from CSQ without inducing saturation of Calcium Green-2 fluorescence (see Fig. 1).

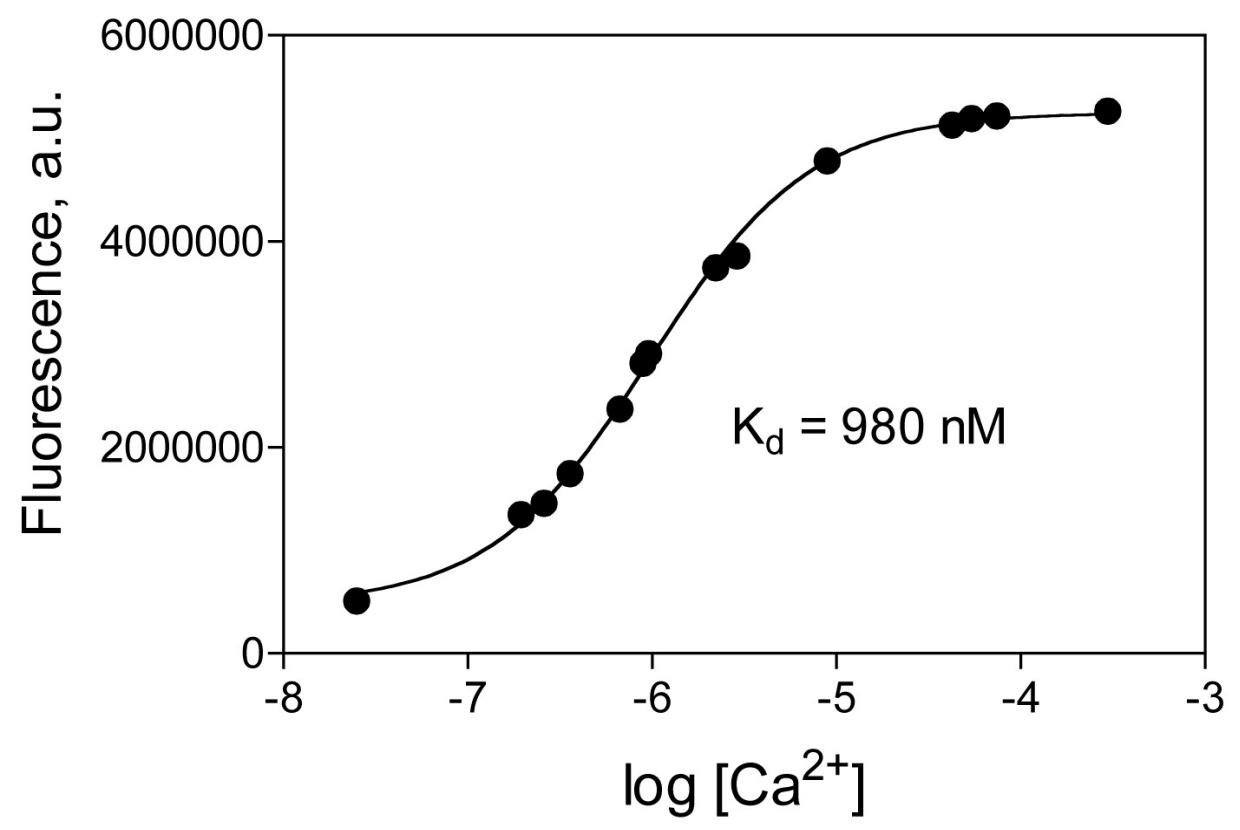

Figure 1. Determination of the $\mathrm{K}_{\mathrm{d}}$ of $\mathrm{Ca}^{2+}$ binding to Calcium Green-2. Calcium Green-2 fluorescence was measured with $\lambda_{\mathrm{ex}}=536 \mathrm{~nm}, \lambda_{\mathrm{em}}=506 \mathrm{~nm}$. Solutions contained $90 \mathrm{nM}$ Calcium Green-2 in $0.1 \mathrm{M} \mathrm{KCl}, 20 \mathrm{mM}$ MOPS-Tris, $\mathrm{pH} 7.2,0.2 \mathrm{mg}$ per $\mathrm{ml}$ of triad-enriched SR vesicles and varying free $\left[\mathrm{Ca}^{2+}\right]$, checked with a calcium electrode. 


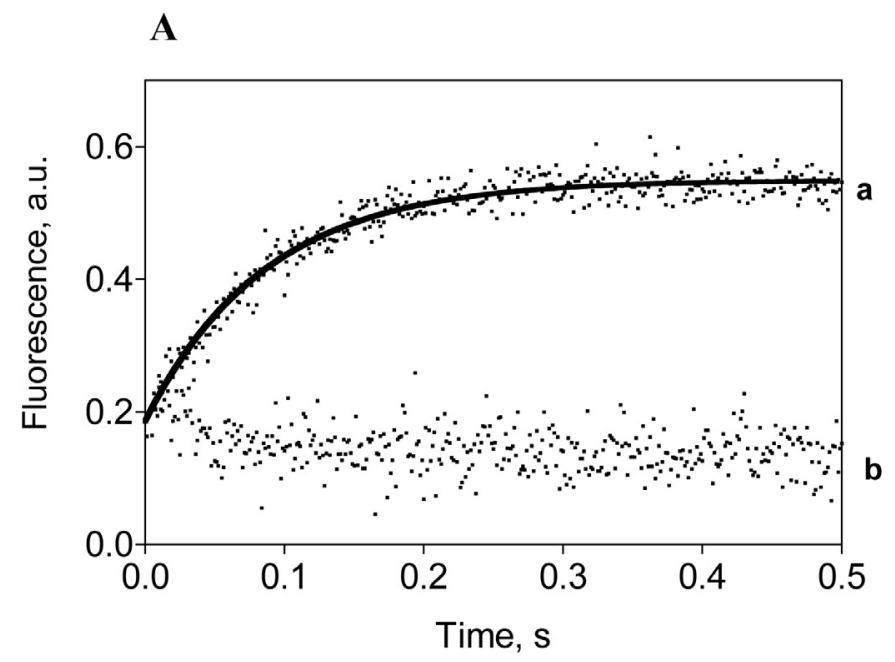

B

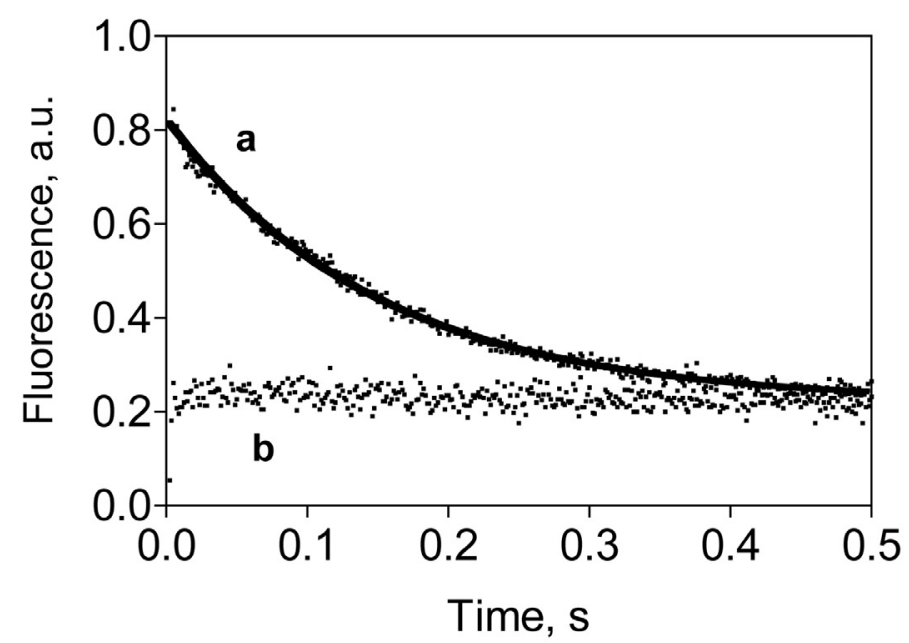

Figure 2. Kinetics of calcium dissociation (A) and intrinsic fluorescence changes (B) for purified calsequestrin in solution. A: Values of Calcium Green-2 fluorescence averaged from 8 independent traces are shown. In a, data obtained after mixing a solution containing calsequestrin equilibrated with $\mathrm{Ca}^{2+}$ with a $\mathrm{Ca}^{2+}$-free solution followed a single exponential function with $\mathrm{k}=11.6 \mathrm{~s}^{-1}$. In $\mathbf{b}$, data correspond to mixing the same solutions as above, except that the $\mathrm{Ca}^{2+}$-containing solution was devoid of calsequestrin. B: Conditions were the same as in $\mathbf{A}$, except that fluorescence was determined with $\lambda_{\text {ex }}$ $=295 \mathrm{~nm}$ to follow intrinsic fluorescence changes. Values, averaged from 5 independent traces, followed a single exponential function with $\mathrm{k}=6.7 \mathrm{~s}^{-1}$. For further details, see text.

Intrinsic fluorescence changes of purified CSQ in solution

Parallel experiments revealed that CSQ intrinsic fluorescence decreased rapidly after mixing, as above, CSQ equilibrated with $\mathrm{Ca}^{2+}$ with the BAPTA containing solution. The intrinsic fluorescence decrease followed a mono-exponential function, with $\mathrm{k}=6.7 \mathrm{~s}^{-1}$ (Fig. 2B, trace a). Mixing just the two solutions, without CSQ, did not produce a significant change in fluorescence (Fig. 2B, trace b).

These combined results suggest that $\mathrm{Ca}^{2+}$ dissociation from purified CSQ in solution is a faster process $\left(\mathrm{t}_{1 / 2}=60 \mathrm{~ms}\right)$ than the changes in intrinsic fluorescence $\left(\mathrm{t}_{1 / 2}=103 \mathrm{~ms}\right)$. 
Calcium dissociation from CSQ forming part of junctional face membranes

Inside the SR lumen, CSQ forms a network and is anchored to the JFM (FranziniArmstrong et al., 1987; Maguire et al., 1997), presumably through its interactions with triadin and junctin. Due to the SR permeability barrier to calcium, direct determination of $\mathrm{Ca}^{2+}$ dissociation from CSQ present in the lumen of intact junctional SR vesicles with an extravesicular $\mathrm{Ca}^{2+}$ indicator is not possible in our conditions. Thus, to compare the dissociation rate of $\mathrm{Ca}^{2+}$ from CSQ in conditions close to the physiological situation, in which CSQ is present at high density, we measured $\mathrm{Ca}^{2+}$ dissociation from CSQ forming part of JFM. The JFM fraction has CSQ still attached to it but does not represent a permeability barrier. Accordingly, direct measurements of $\mathrm{Ca}^{2+}$ dissociation kinetics are possible with our stopped flow system.

As illustrated in a gel stained with Coomassie blue (Fig. 3, top panel), the JFM fraction (lane 5) is significantly enriched in CSQ when compared to the SR vesicles (lane 1); the JFM fraction is practically devoid of Ca-ATPase, which is present in the Triton X-100 supernatant (lane 3). Incubation of JFM with EGTA resulted in extraction of CSQ from the JFM (lane 4) to the EGTA-supernatant (lane 2). The lower panel of Figure 3 shows the same gel after removing the Coomassie blue stain and staining with Stains-All, which stains blue calcium-binding proteins such as CSQ and pink all other proteins.

A solution containing $3.3 \mathrm{mg}$ per $\mathrm{ml}$ of JFM previously equilibrated with $2.2 \mathrm{mM}$ $\mathrm{CaCl}_{2}$ for $36 \mathrm{~h}$ (see Materials and Methods) was mixed 1: 10 with a solution containing Calcium Green-2 plus $0.286 \mathrm{mM}$ BAPTA. Following mixing, protein concentration was $0.3 \mathrm{mg} / \mathrm{ml}$, total $\mathrm{Ca}^{2+}$ was $0.2 \mathrm{mM}$, and initial free $\left[\mathrm{Ca}^{2+}\right]$ was $0.67 \mu \mathrm{M}$; solution $\left[\mathrm{Ca}^{2+}\right]$ increased rapidly following a monoexponential function with $\mathrm{k}=106.1 \mathrm{~s}^{-1}$ (Fig. 4A, trace a). Dilution 1: 10 of a solution containing $3.3 \mathrm{mg}$ per $\mathrm{ml}$ of CSQfree JFM previously equilibrated with 2.2 $\mathrm{mM}\left[\mathrm{Ca}^{2+}\right]$ with a solution containing 0.286
mM BAPTA did not produce a significant increase in Calcium Green-2 fluorescence but caused a very small and fast fluorescence decrease that was completed in less than $10 \mathrm{~ms}$ (Fig. 4A, trace b).

Upon mixing, the final JFM concentration became $0.3 \mathrm{mg} / \mathrm{ml}$, of which about $50 \%$ corresponds to CSQ (Fig. 3) giving a final CSQ concentration of $3 \mu \mathrm{M}$. Assuming that at $2 \mathrm{mM}\left[\mathrm{Ca}^{2+}\right] \mathrm{CSQ}$ was $67 \%$ saturated with $\mathrm{Ca}^{2+}(33 \mathrm{~mol} / \mathrm{mol})$, it can be estimated that solution $\left[\mathrm{Ca}^{2+}\right]$ should have increased by about $100 \mu \mathrm{M}$. But considering BAPTA (final concentration $0.26 \mathrm{mM}$ ), it can be calculated that solution $\left[\mathrm{Ca}^{2+}\right]$ increased only to $4.1 \mu \mathrm{M}$. Again, this $\mathrm{Ca}^{2+}$ range is enough to induce complete dissociation of calcium from CSQ without inducing saturation of Calcium Green-2 fluorescence (Fig. 1).

In parallel experiments, mixing the same solutions as above revealed that the intrinsic fluorescence of JFM decreased rapidly after mixing JFM equilibrated with $\mathrm{Ca}^{2+}$ with the BAPTA-containing solution (Fig. 4B, trace a). In this case, the fluorescence decay was not well adjusted by a single exponential function (broken line, Fig. 4B, inset) but was better adjusted by a double-exponential function with $\mathrm{k} 1=$ $54.8 \mathrm{~s}^{-1}$ and $\mathrm{k} 2=7.4 \mathrm{~s}^{-1}$. The magnitude of each exponential component was about equal. It is noteworthy that the $\mathrm{k} 2$ value was not significantly different from the $\mathrm{k}$ value of the intrinsic fluorescence change exhibited by CSQ in solution. Similar dilution of CSQ-free JFM with the BAPTAcontaining solution produced only a small fluorescence decrease (Fig. 4B, trace b), suggesting that essentially all intrinsic fluorescence changes displayed by JFM were contributed by CSQ.

A summary of values obtained in several experiments is given in Table 1. The half time of calcium dissociation from CSQ forming part of the JFM was $\leq 6.4 \mathrm{~ms}$, at $25^{\circ} \mathrm{C}$. It is likely that calcium dissociation will be even faster at $37^{\circ} \mathrm{C}$. These results imply that calcium dissociation from CSQ in vivo is not rate limiting for calcium release from the SR.

The results summarized in Table 1 also indicate that calcium dissociation from 
CSQ, either in solution or forming part of the JFM, was faster than the associated intrinsic fluorescence changes. These results indicate that the structural rearrangements of CSQ that follow $\mathrm{Ca}^{2+}$ dissociation and that originate the intrinsic florescence decrease occur with some delay after $\mathrm{Ca}^{2+}$ dissociation. Noteworthy, $\mathrm{Ca}^{2+}$ dissociation from CSQ and the subsequent intrinsic fluorescence changes were faster when CSQ was still attached to JFM than in solution. It has been reported that CSQ is present in the SR lumen in a wide range of high molecular mass clusters (Maguire et al., 1997). Thus, our findings suggest that when present at high concentrations in a restricted space, such as when attached to the JFM, CSQ may also form clusters from which calcium would dissociate in a cooperative fashion.

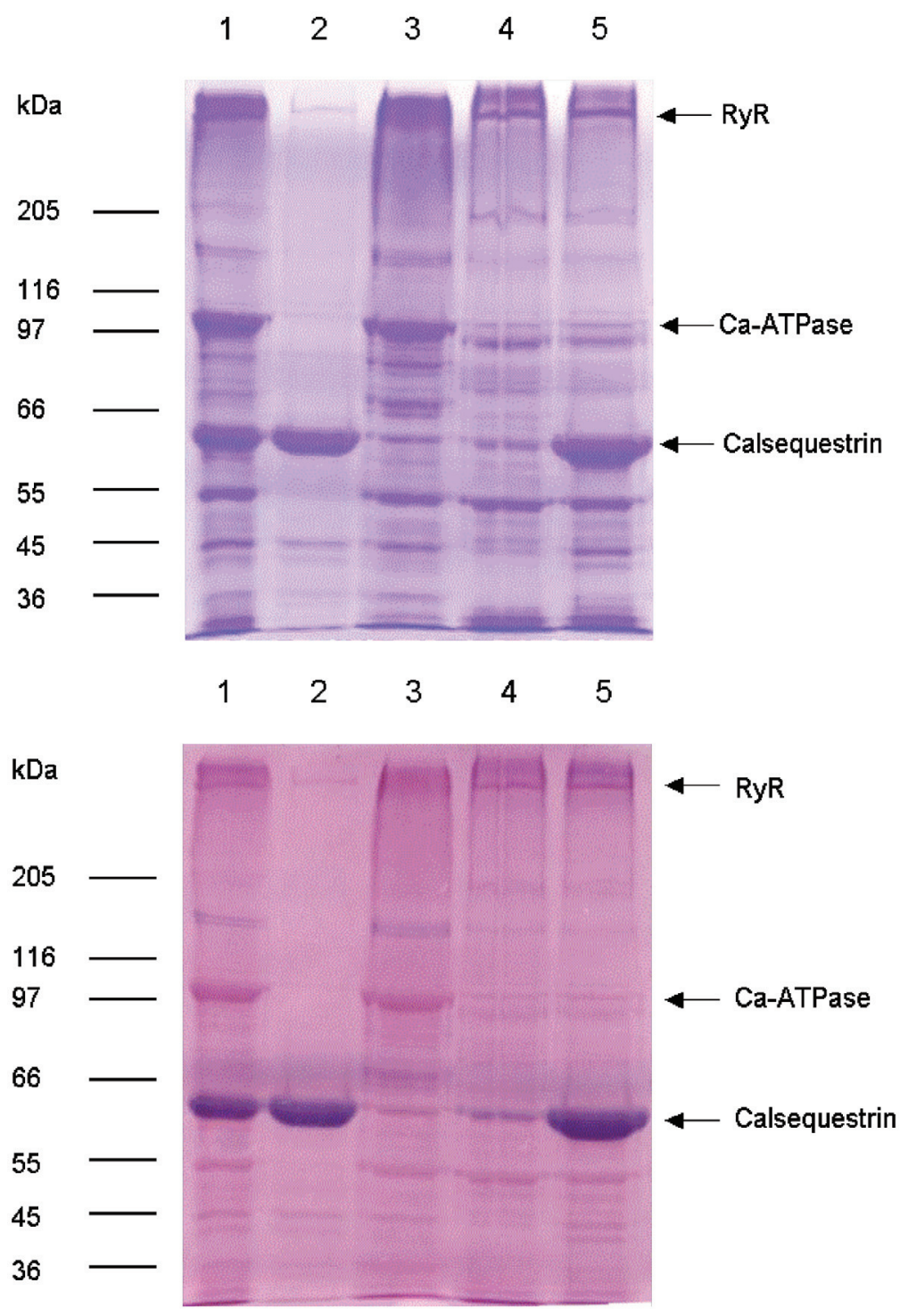

Figure 3. Protein composition of JFM as determined by SDS-electrophoresis. Top panel, 2-12\% polyacrylamide gradient gel stained with Coomassie Blue. Lower panel, the same gel, after removal of the Coomassie Blue stain and staining with Stains All. Lane 1: Triad-enriched SR vesicles. Lane 2: Supernatant of JFM after CSQ extraction. Lane 3: supernatant of SR vesicles extracted with Triton X-100 to prepare JFM. Lane 4: JFM devoid of CSQ. Lane 5: JFM. 

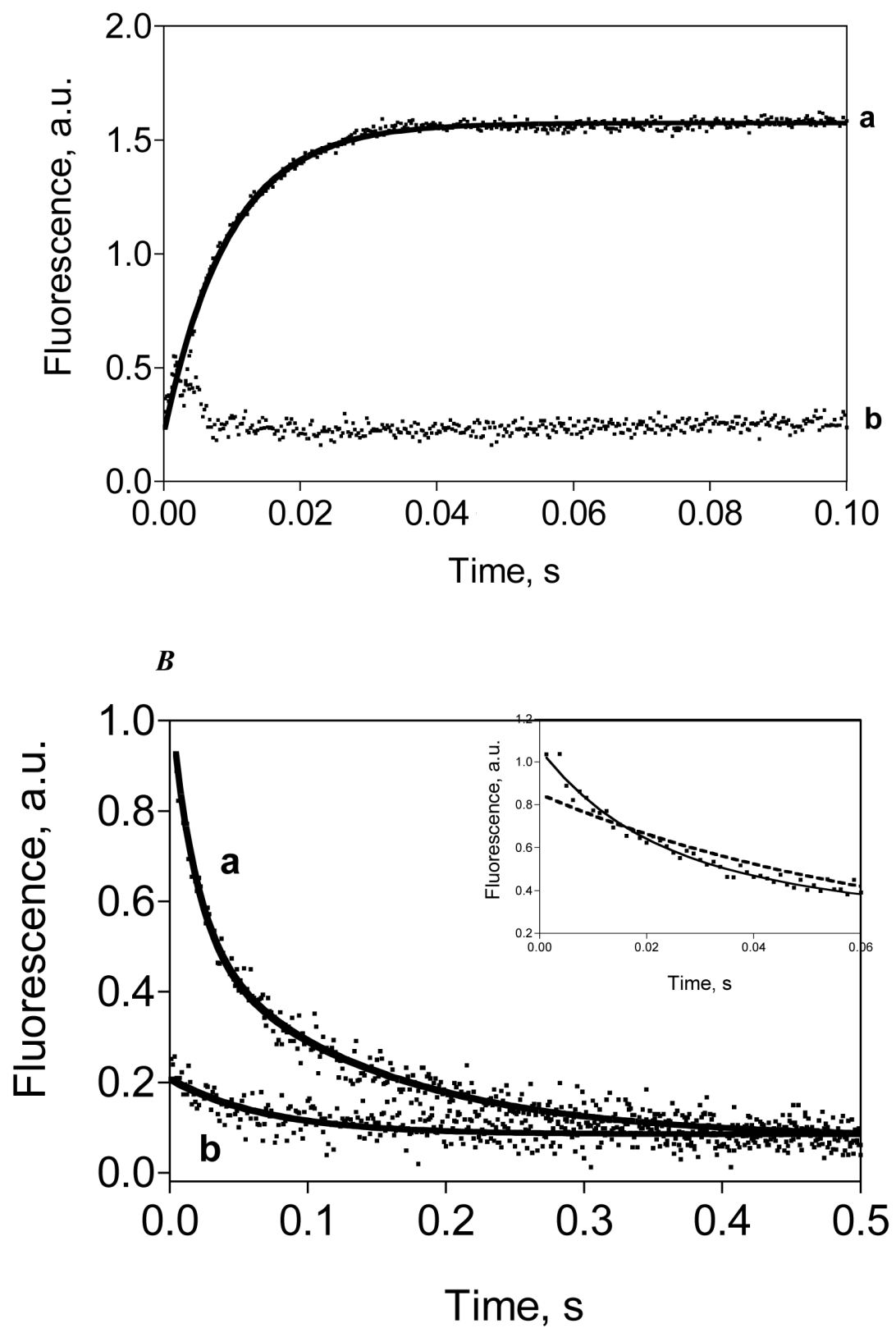

Figure 4. Kinetics of calcium dissociation from JFM (A) and the associated intrinsic fluorescence changes (B). A: Values of Calcium Green-2 fluorescence averaged from 4 independent traces are shown. In a, data obtained after mixing JFM equilibrated with $\mathrm{Ca}^{2+}$ with a $\mathrm{Ca}^{2+}$-free solution followed a single exponential function with $\mathrm{k}=106.1 \mathrm{~s}^{-1}$. In $\mathbf{b}$, data correspond to mixing the same solutions as above, except that the $\mathrm{Ca}^{2+}$-containing solution contained JFM devoid of CSQ. B: Conditions were the same as in A, except that fluorescence was determined with $\lambda_{\text {ex }}=295 \mathrm{~nm}$ to follow intrinsic fluorescence changes. In a, values from JFM and averaged from 4 independent traces followed a double exponential function with $\mathrm{k} 1=54.8 \mathrm{~s}^{-1}(55.4 \%$ of the total fluorescence change) and $\mathrm{k} 2=7.4 \mathrm{~s}^{-1}$ ( $44.6 \%$ of the total fluorescence change). Values in $\mathbf{b}$ correspond to CSQfree JFM. For further details, see text. 
TABLE 1

Rate constants of calcium dissociation from calsequestrin and of the associated intrinsic fluorescence changes

\begin{tabular}{lcc}
\hline & $\begin{array}{c}\text { Rate Constant of } \\
\text { Calcium Dissociation, } \mathrm{s}^{-1}\end{array}$ & $\begin{array}{c}\text { Rate Constant of } \\
\text { Intrinsic Fluorescence change, } \mathrm{s}^{-1}\end{array}$ \\
\hline Calsequestrin in Solution & $11.5 \pm 0.3(\mathrm{n}=9)$ & $6.5 \pm 0.1(\mathrm{n}=5)$ \\
Junctional Face Membranes & $109.0 \pm 1.4(\mathrm{n}=4)$ & $\mathrm{k} 1=54.12 \pm 2.3(55.4 \%)$ \\
& & $\mathrm{k} 2=6.88 \pm 0.29(44.6 \%)(\mathrm{n}=4)$ \\
\hline
\end{tabular}

Data represent Mean \pm S.E. See text for further details.

In response to RyR activation by submaximal concentrations of releasing agents, CSQ unbinds $\mathrm{Ca}^{2+}$ (and presumably undergoes a significant change in conformation, as determined here) before $\mathrm{Ca}^{2+}$ is released from the SR (Ikemoto et al., 1991). These results raise the possibility that the E-C coupling signal transmitted from the transverse tubule voltage sensors to RyR channels also may be sensed by CSQ, resulting in fast $\mathrm{Ca}^{2+}$ dissociation from CSQ. As discussed above, following $\mathrm{Ca}^{2+}$ dissociation, CSQ would loose its $\alpha$ helical content to adopt a random coil conformation that would inhibit RyR activity. If this mechanism operates during E-C coupling, CSQ via $\mathrm{Ca}^{2+}$-dependent conformational changes may control how long RyR channels remain open after activation. Clearly, more experimental evidence is needed to investigate in further molecular detail how CSQ contributes to regulate $\mathrm{Ca}^{2+}$ release during E-C coupling in skeletal and cardiac muscle.

\section{ACKNOWLEDGEMENTS}

Paulina Donoso's critical reading of this manuscript is gratefully acknowledged. This work was supported by FONDAP Center for Molecular Studies of the Cell, Fondo Nacional de Investigación Científica y Tecnológica (FONDECYT) 15010006.

\section{REFERENCES}

BEARD NA, SAKOWSKA MM, DULHUNTY AF, LAVER DR (2002) Calsequestrin is an inhibitor of skeletal muscle ryanodine receptor calcium release channels. Biophys J 82: 310-320
BEARD NA, LAVER DR, DULHUNTY AF (2004) Calsequestrin and the calcium release channel of skeletal and cardiac muscle. Prog Biophys Mol Biol 85: 33-69

CALA SE, JONES LR (1983) Rapid purification of calsequestrin from cardiac and skeletal muscle sarcoplasmic reticulum vesicles by $\mathrm{Ca} 2+$-dependent elution from phenyl-sepharose. J Biol Chem 258: 11932-11936

CAMPBELL KP, MACLENNAN DH, JORGENSEN AO (1983) Staining of the Ca2+-binding proteins, calsequestrin, calmodulin, troponin C, and S-100, with the cationic carbocyanine dye "Stains-all". J Biol Chem 258: 11267-11273

COSTELLO B, CHADWICK C, SAITO A, CHU A, MAURER A, FLEISCHER S (1986) Characterization of the junctional face membrane from terminal cisternae of sarcoplasmic reticulum. J Cell Biol 103: 741-753

COZENS B, REITHMEIER RA (1984) Size and shape of rabbit skeletal muscle calsequestrin. J Biol Chem 259: 6248-6252

DONOSO P, PRIETO H, HIDALGO C (1995) Luminal calcium regulates calcium release in triads isolated from frog and rabbit skeletal muscle. Biophys $\mathrm{J} 68$ : 507-515

DONOSO P, BELTRÁN M, HIDALGO C (1996) Luminal $\mathrm{pH}$ regulates calcium release kinetics in sarcoplasmic reticulum vesicles. Biochemistry 35: 13419-13425

FRANZINI-ARMSTRONG C, KENNEY LJ, VARRIANOMARSTON E (1987) The structure of calsequestrin in triads of vertebrate skeletal muscle: A deep-etch study. J Cell Biol 105: 49-56

GUO W, CAMPBELL KP (1995) Association of triadin with the ryanodine receptor and calsequestrin in the lumen of the sarcoplasmic reticulum. J Biol Chem 270: 9027-9030

GYORKE S, GYORKE I, TERENTYEV D, VIATCHENKO-KARPINSKI S, WILLIAMS SC (2004) Modulation of sarcoplasmic reticulum calcium release by calsequestrin in cardiac myocytes. Biol Res 37: 603-607

HARTREE EF (1972) Determination of protein: A modification of the Lowry method that gives a linear photometric response. Anal Biochem 48: 422-427

HE Z, DUNKER AK, WESSON CR, TRUMBLE WR (1993) $\mathrm{Ca}(2+)$-induced folding and aggregation of skeletal muscle sarcoplasmic reticulum calsequestrin. The involvement of the trifluoperazine-binding site. J Biol Chem 268: 24635-24641

HIDALGO C, JORQUERA J, TAPIA V, DONOSO P (1993) Triads and transverse tubules isolated from skeletal muscle contain high levels of inositol 1,4,5trisphosphate. J Biol Chem 268: 15111-15117 
HIDALGO C, DONOSO P, RODRÍGUEZ PH (1996) Protons induce calsequestrin conformational changes. Biophys J 71: 2130-2137

IKEMOTO N, BHATNAGAR GM, NAGY B, GERGELY J (1972) Interaction of divalent cations with the 55,000dalton protein component of the sarcoplasmic reticulum. Studies of fluorescence and circular dichroism. J Biol Chem 247: 7835-7837

IKEMOTO N, RONJAT M, MESZAROS LG, KOSHITA M (1989) Postulated role of calsequestrin in the regulation of calcium release from sarcoplasmic reticulum. Biochemistry 28: 6764-6771

IKEMOTO N, ANTONIU B, KANG JJ, MESZAROS LG, RONJAT M (1991) Intravesicular calcium transient during calcium release from sarcoplasmic reticulum. Biochemistry 30: 5230-5237

LAEMMLI UK (1970) Cleavage of structural proteins during the assembly of the head of bacteriophage T4. Nature 227: 680-685

LAMB GD, CELLINI MA, STEPHENSON DG (2001) Different $\mathrm{Ca} 2+$ releasing action of caffeine and depolarisation in skeletal muscle fibres of the rat. J Physiol 531: 715-728

MACLENNAN DH, WONG PT (1971) Isolation of a calcium-sequestering protein from sarcoplasmic reticulum. Proc Natl Acad Sci USA 68: 1231-1235

MAGUIRE PB, BRIGGS FN, LENNON NJ OHLENDIECK K (1997) Oligomerization is an intrinsic property of calsequestrin in normal and transformed skeletal muscle. Biochem Biophys Res Commun 240: 721-727

MURRAY BE, OHLENDIECK K (1998) Complex formation between calsequestrin and the ryanodine receptor in fast- and slow-twitch rabbit skeletal muscle. FEBS Lett 429: 317-322

ROJAS E, HIDALGO C (1968) Effect of temperature and metabolic inhibitors on ${ }^{45} \mathrm{Ca}$ outflow in squid giant axons. Biochim Biophys Acta 163: 550-556

WANG S, TRUMBLE WR, LIAO H, WESSON CR, DUNKER AK, KANG CH (1998) Crystal structure of calsequestrin from rabbit skeletal muscle sarcoplasmic reticulum. Nat Struct Biol 5: 476-483

ZHANG L, KELLEY J, SCHMEISSER G, KOBAYASHI YM, JONES LR (1997) Complex formation between junctin, triadin, calsequestrin, and the ryanodine receptor. Proteins of the cardiac junctional sarcoplasmic reticulum membrane. J Biol Chem 272: 23389-23397 
